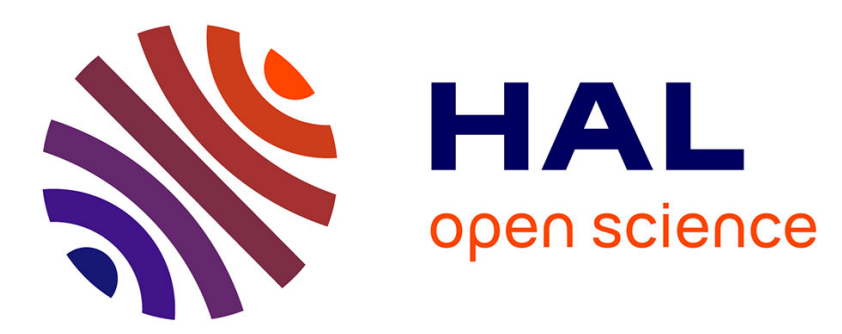

\title{
Small-angle neutron scattering of multiphase secondary hardening steels
}

Mikael Perrut, Marie-Helene Mathon, Denis Delagnes

\section{To cite this version:}

Mikael Perrut, Marie-Helene Mathon, Denis Delagnes. Small-angle neutron scattering of multiphase secondary hardening steels. Journal of Materials Science, 2012, 47 (4), pp.1920-1929. 10.1007/s10853011-5982-x . hal-01687332

\section{HAL Id: hal-01687332 \\ https://hal.science/hal-01687332}

Submitted on 15 Mar 2019

HAL is a multi-disciplinary open access archive for the deposit and dissemination of scientific research documents, whether they are published or not. The documents may come from teaching and research institutions in France or abroad, or from public or private research centers.
L'archive ouverte pluridisciplinaire HAL, est destinée au dépôt et à la diffusion de documents scientifiques de niveau recherche, publiés ou non, émanant des établissements d'enseignement et de recherche français ou étrangers, des laboratoires publics ou privés. 


\title{
Small-angle neutron scattering of multiphase secondary hardening steels
}

\author{
Mikaël Perrut • Marie-Hélène Mathon • \\ Denis Delagnes
}

\begin{abstract}
Alloying secondary hardening steels with $\mathrm{Ni}$ and $\mathrm{Al}$ allows the precipitation of an intermetallic phase B2-NiAl in addition to the classical secondary carbides precipitation, adding up the advantages of both types of precipitation (Erlach et al. Mater Sci Eng A 429:96, 2006; Erlach et al. Int J Microstruct Mater Prop 3:373, 2008). Small-angle neutron scattering experiments were carried out to analyse the nanometric scale precipitation of a martensitic steel containing a double precipitation of carbides and intermetallic phase. The precipitates size, volume fraction and chemical composition for both carbides and intermetallic phases according to the tempering time were estimated and discussed. In addition, experimental cobaltfree grades containing a single precipitation or a double precipitation were manufactured and analysed. Relationship between measured tensile yield strengths and the nanometre-sized particles are suggested, showing that both populations of precipitates have a relevant impact on the mechanical properties.
\end{abstract}

M. Perrut · M.-H. Mathon

Laboratoire Léon Brillouin, CEA-CNRS, IRAMIS,

91191 Gif-sur-Yvette, France

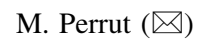

ONERA, DMSM, 29 Avenue de la Division Leclerc, BP 72, 92322 Châtillon, France

e-mail: mikael.perrut@onera.fr

D. Delagnes

Ecole des Mines Albi; ICA (Institut Clément Ader),

Université de Toulouse, Campus Jarlard, 81013 Albi, France

\section{Introduction}

Design of new materials with high mechanical properties has been focused on the strengthening of existing steels by nanometre-scale precipitates. It is needed to find an equilibrium between microstructural stability, high strength and ductility [1]. In order to define optimal materials by modifying the chemical composition and heat treatments, microstructural characterisations at the nanometre scale are necessary, as the precipitation mechanisms leading to structural hardening need to be understood.

As the analysed volume is several cubic millimetres, Small-angle neutron scattering (SANS) is a very relevant technique, giving statistically quantitative measurements of the precipitate size, shape, volume fraction, number density, atomic compositions in a wide range of sizes. The SANS intensity is directly proportional to a contrast term representing the variation of the scattering length between the precipitates and the matrix. First, the anisotropic magnetic intensity induced by the iron atom magnetic moment is on the same order as the nuclear scattered intensity. These two contrasts give complementary information on the chemical composition of the particles. Second, the iron scattering length being very different from the scattering lengths of the major alloying elements in the investigated steels, SANS technique offers advantageous contrasts.

The main goal of this article is to analyse the modification of mechanical properties of classical secondary hardening steels by alloying them with $\mathrm{Ni}$ and $\mathrm{Al}$, which induce intermetallic phases formation concomitant to the carbides precipitation. The industrial reference alloy of the study, Alloy 1014, has the same composition as the GE1014 alloy [2] that has been developed in the 90 s by General Electric for turbine shaft applications in aircraft engines 
[3]. The GE1014 grade is the results of 40 years of research on steels for aeronautical applications. First of all, steels hardened by secondary carbides containing chromium and molybdenum were developed (HY180, AF1410, AERMET 100,310 and 340) [4-6]. On the other hand, during the two decades 1950-1970, intensive research programs for space applications have led to the development of maraging steels, presenting a better balance of properties but a higher cost. These steels are carbon free, hardened by intermetallic phases such as $\mathrm{Ni}_{3} \mathrm{Mo}$ and $\mathrm{Ni}_{3} \mathrm{Ti}$.

Thermodynamic simulations, as well as previous experimental studies performed on similar steels, suggested that the precipitated phases are $M_{2} C$ carbides $(\mathrm{M}=\mathrm{Cr}$, $\mathrm{Mo}, \mathrm{Fe})$ and $\mathrm{B} 2$-ordered NiAl crystals.

\section{Experimental methods}

\section{Materials}

All steels were elaborated by the Aubert and Duval Company. The nominal composition of the reference Alloy 1014 industrial alloy is shown in Table 1. GE1014 microstructural studies do not appear in any scientific articles, but some aspects of its mechanical properties are examined and compared with the Maraging steel MA250 in [7]. The AlloyM2C, AlloyNiAl, AlloyMix cobalt-free experimental martensitic steels have a similar basic composition (Table 1). Aluminium in AlloyM2C and Carbon in AlloyNiAl were suppressed, so only carbides are supposed to precipitate in AlloyM2C, whereas intermetallic precipitation alone is expected in AlloyNiAl. AlloyStd is carbon free and aluminium free, hence providing a standard precipitation-free sample. The same precipitation heat treatment was applied for each grade: $900{ }^{\circ} \mathrm{C}$ for $1 \mathrm{~h}$, followed by a cryogenic treatment at $-80{ }^{\circ} \mathrm{C}$ for $8 \mathrm{~h}$. The alloy is then tempered at $200{ }^{\circ} \mathrm{C}$ for $8 \mathrm{~h}$. Finally, a second tempering at $500{ }^{\circ} \mathrm{C}$ is performed. The intensive precipitation process is expected during this last step. Several second tempering durations were selected to quantify the precipitation kinetics: no tempering, $10 \mathrm{~min}, 20 \mathrm{~min}, 1 \mathrm{~h}, 4 \mathrm{~h}, 10$ $\mathrm{h}, 20 \mathrm{~h}$ and $100 \mathrm{~h}$.

Table 1 Nominal composition (wt.\%) of the Alloy1014 alloy, indicated symbols are attributed to the corresponding grades in all plots of this article

\begin{tabular}{lllllllll}
\hline & Symbol & $\mathrm{Fe}$ & $\mathrm{C}$ & $\mathrm{Cr}$ & $\mathrm{Co}$ & $\mathrm{Ni}$ & $\mathrm{Mo}$ & $\mathrm{Al}$ \\
\hline Alloy1014 & $\bullet$ & 71 & 0.2 & 2.5 & 10 & 14 & 1.4 & 0.9 \\
AlloyStd & $\triangleright$ & 86.6 & 0.2 & 2.5 & 0 & 10.7 & 0 & 0 \\
AlloyM2C & $\square$ & 85.4 & 0.2 & 2.5 & 0 & 10.5 & 1.4 & 0 \\
AlloyNiAl & $\mathbf{\square}$ & 84.9 & 0 & 2.5 & 0 & 11.6 & 0 & 1 \\
AlloyMix & $\bigcirc$ & 83.4 & 0.2 & 2.5 & 0 & 11.5 & 1.4 & 1 \\
\hline
\end{tabular}

Tensile yields strength according to the tempering time of each alloy were measured in the Aubert and Duval Company and Institut Clément Ader laboratories. See "Precipitation hardening" section.

\section{SANS experiments}

The neutron scattering experiments were performed on PAXE and PAXY small angle spectrometers of the ORPHEE facility, at the Laboratoire Léon Brillouin. A saturating magnetic field $H=1.7 T$ was applied perpendicularly to the neutron incident beam.

Two different setups were used for the SANS experiments: the sample-detector distances were 5 and $2 \mathrm{~m}$ with a selected wavelength of 9 and $6 \AA$, respectively. Both $q$ ranges overlap confirmed that the absolute values of the measured scattered intensities are correct and the absence of multiple scattering. Dimensions of the sample are $10 \times 10 \times 0.8 \mathrm{~mm}^{3}$. The analysed volume is a little smaller due to collimation, approximately reduced to $30 \mathrm{~mm}^{3}$. The experiments required 1-3 h of counting for each sample and for each spectrometer configuration, depending on the tempering time.

The scattered intensity measured in a reference sample with no $500{ }^{\circ} \mathrm{C}$ tempering and, consequently, no secondary precipitation was subtracted from the scattered intensities of every tempered samples in order to eliminate incoherent scattering and contributions from inhomogeneities such as free surfaces or grain boundaries. Background correction and calibration were performed as described in [8], then the obtained intensity per unit volume for a two-phased system (single-phased precipitation) is given by:

$$
\begin{aligned}
I(q, \alpha) & =\frac{1}{V_{\mathrm{S}}} \frac{d \Sigma}{d \Omega}(q) \\
& =f_{p}\left(\Delta \rho_{\mathrm{nucl}}^{2}+\Delta \rho_{\mathrm{mag}}^{2} \sin ^{2} \alpha\right)|F(q)|^{2} S(q)
\end{aligned}
$$

where $V_{\mathrm{S}}$ is the sample irradiated volume, $f_{\mathrm{p}}$ the volume fraction of precipitates, $\Delta \rho_{\text {nucl }}$ and $\Delta \rho_{\text {mag }}$, respectively, the nuclear and magnetic contrasts between the precipitates and the matrix, $\alpha$ the angle between the scattering vector and the sample magnetisation, $F(q)$ the form factor depending on the precipitates shape and size, $S(q)$ the structure factor depending on the spatial arrangement of the precipitates.

The ferritic matrix of these alloys is ferromagnetic, which is not the case of the $M_{2} C$ carbides and the $F e_{x} N i_{y} A l_{1-x-y}$ intermetallic phases because of their relatively low iron content. Hence, the magnetic scattered intensity, which is anisotropic and which can be deduced from the raw data, allows determining relevant information on the chemical composition of the precipitates. 
Size distributions, shapes and volume fractions are determined by considering only the magnetic contribution to scattering, whereas the nuclear contribution is used to verify the obtained results and to estimate the chemical compositions of the particles. Magnetic scattered intensity is calculated by subtraction of the parallel $(\alpha=0)$ contribution to the perpendicular $(\alpha=\pi / 2)$ contribution. The nuclear contribution is directly obtained with the intensity scattered parallel to the magnetic field. When the investigated material contains several types of precipitates, the sum of each main contribution is considered. Equations 2 and 3 could be written as follows:

$I_{\text {mag }}(q)=S(q) \sum_{i} f_{p i} \Delta \rho_{\text {magi }}^{2}\left|F_{i}(q)\right|^{2}$

and

$I_{\text {nucl }}(q)=S(q) \sum_{i} f_{p i} \Delta \rho_{\text {nucli }}^{2}\left|F_{i}(q)\right|^{2}$

where the index $i$ relates to each type of precipitates. Structure factor concerns the spatial arrangement of the whole population of precipitates. This structure factor is approximated using a hard-sphere model. The contrasts $\Delta \rho_{\text {magi }}$ are often equal to each other, as non-magnetic precipitates correspond to magnetic holes in the matrix. Consequently, Eq. 2 can be simplified (for $i \leq 2$ ):

$I_{\mathrm{mag}}(q)=S(q) \Delta \rho_{\mathrm{mag}}^{2}\left\{f_{p 1}\left|F_{1}(q)\right|^{2}+f_{p 2}\left|F_{2}(q)\right|^{2}\right\}$

where the contrast $\Delta \rho_{\mathrm{mag}}^{2}$ is the square of the magnetic scattering length density of the matrix. $I_{\text {mag }}(q)$ does not depend on the chemical composition of the precipitates. Therefore, quantitative volume fractions can be obtained without any hypothesis on these compositions.

The scattering length densities calculation are based on the extrapolation of bibliographical data, including lattice parameters [9], neutron scattering cross-sections [10] and magnetic moments [11, 12]. Magnetic moments are generally difficult to evaluate because of the complexity of the chemical compositions of the alloys. A simple dilution law would lead to $\bar{\mu}=\mu_{\mathrm{Fe}}^{0} x_{\mathrm{Fe}}$ where $\mu_{\mathrm{Fe}}^{0}$ equals 2.217 Bohr magneton $\left(\mu_{\mathrm{B}}\right)$ and $x$ is the atomic concentration of the considered element in the matrix. But nickel and cobalt ferromagnetic properties must be taken into account, and the evolution of $\bar{\mu}$ according to $\mathrm{X}$ atomic fraction is approximated by summing individual contributions:

$$
\begin{array}{r}
\bar{\mu}=\mu_{\mathrm{Fe}}^{0}+\Delta \mu_{\mathrm{Fe}-\mathrm{Ni}}\left(C_{\mathrm{Ni}}\right)+\Delta \mu_{\mathrm{Fe}-\mathrm{Co}}\left(C_{\mathrm{Co}}\right) \\
+\left.\frac{d \mu}{d C}\right|_{\mathrm{Al}} C_{\mathrm{Al}}+\left.\frac{d \mu}{d C}\right|_{\mathrm{Cr}} C_{\mathrm{Cr}}
\end{array}
$$

where $C_{X}=x_{X} /\left(x_{X}+x_{\mathrm{Fe}}\right), x$ being the element atomic concentration in the matrix, and $\bar{\mu}$ the mean magnetic moment per atom. The different coefficients are deduced from binary alloys measurements, except for the variation of $\mu$ with $\mathrm{Al}$ content that is extrapolated from ternary $\mathrm{Fe}-\mathrm{Ni}-\mathrm{Al}$ alloys [13]. The corresponding coefficient varies from -3.48 to $-4.07 \mu_{\mathrm{B}}$ depending on $\mathrm{Ni}$ content. Chromium coefficient is constant and equal to $-2.39 \mu_{\mathrm{B}}$ [14]. For Alloy 1014 composition, the mean magnetic moment reaches $2.18 \mu_{\mathrm{B}}$ per atom, meanwhile a simple dilution of iron magnetic moment would give $1.57 \mu_{\mathrm{B}}$ per atom. This strong difference is due to the high content in both $\mathrm{Ni}$ and Co elements. The Ni content in the matrix is reduced by the precipitation of intermetallic phases, but this variation is small (from $13 \%$ at. to $11 \%$ at.) and is balanced by a higher Co content. All changes in matrix composition while tempering were not considered as significant for the calculation of magnetic contrast.

The scattering curves were analysed assuming a form factor including a symmetric normalised gaussian distribution of spheres and ellipsoids. $r_{1}$ and $r_{2}$ are the mean radii, $\sigma_{1}$ and $\sigma_{2}$ are the standard deviations of the gaussian distributions of spheres. Ellipsoids correspond to spheres that are stretched by a factor ell ${ }_{1}$ or ell ${ }_{2}$. Finally, $r_{\mathrm{eq}}$ is the mean sphere-equivalent radius of an ellipsoid distribution:

$r_{\mathrm{eq} i}=r_{i} \sqrt[3]{\mathrm{ell}_{i}}$

The expression of the form factor of a gaussian distribution of ellipsoids defined by $r_{i}, \sigma_{i}$ and $\mathrm{ell}_{i}$ is detailed in the Appendix 1. For diluted alloys (typically $f_{p}<2 \%$ ), it can be assumed that the precipitates are arranged randomly in space, hence the structure factor can be approximated by 1 . If the whole precipitated volume fraction grows over $2 \%$, it is necessary to take into account the interaction between the precipitates. The general expression of the structure factor is defined as follows:

$S(q)=1+N \int_{V}(g(r)-1) \frac{\sin q r}{q r} 4 \pi r^{2} d r$

where $N$ is the number density of particles, $V$ the sample volume, $g(r)$ the radial pair distribution function. In our case, we used a monodisperse hard-sphere model with the Percus-Yevick closure relationship [15, 16]. The distribution function $g(r)$, given in $[17,18]$, is a function of the hard-sphere volume fraction $\eta$ and the hard-sphere radius $R$. For single-phased spherical precipitation, $R$ is taken equal to the mean radius of the gaussian distribution of spheres. For multiphase spherical precipitation, as long as the mean radii of both distributions were similar, we assumed $R \approx r_{1} \approx r_{2}$ and $\eta=f_{p 1}+f_{p 2}$. Otherwise, the structure factor was chosen equal to that of the main precipitated phase. As far as the double precipitation is concerned, the number density of the main phase (intermetallics) is ten times higher than the one of the minority phase (carbides), and $S(q) \approx S_{\mathrm{FeNiAl}}(q)$. As far as 
ellipsoids are concerned, their mean size is always high and the product $q r$ is largely superior to unity. Consequently, the structure factor is close to unity over a wide range of the investigated $q$-range.

Equation 4 was used to fit the experimental data. The mean size of the particles, as well as the full width at the half maximum of the gaussian distributions were also obtained. Volume fractions were estimated as well as the precipitates number densities $N_{p i}$ :

$N_{p i}=\frac{3 f_{p i}}{4 \pi\left(r_{i}^{2}+3 \sigma_{i}^{2}\right) r_{i} \mathrm{ell}_{i}}$

For chemically and magnetically homogeneous particles, the $A$-ratio depends on the chemical composition, magnetisation and atomic density variations between precipitates and the matrix, and is given by:

$A=\frac{I_{\text {nucl }}(q)+I_{\text {mag }}(q)}{I_{\text {nucl }}(q)}=\frac{\Delta \rho_{\text {nucl }}^{2}+\Delta \rho_{\mathrm{mag}}^{2}}{\Delta \rho_{\text {nucl }}^{2}}$

When there are two types of precipitates in the samples, the $A$-ratio defined by Eq. 9 is not constant neither a simple function of $q$. Nuclear contrasts are deduced by varying $\Delta \rho_{\text {nucl1 }}^{2}$ and $\Delta \rho_{\text {nucl2 }}^{2}$ in order to fit the measured nuclear intensity using Eq. 3, the other parameters being estimated before thanks to magnetic contribution. From results obtained by TEM observations associated with electronic diffraction and by atom probe observations, the $\mathrm{M}_{2} \mathrm{C}$ stoichiometry is supposed to be exact, and different additional possibilities of varying $\mathrm{M}=(\mathrm{Fe}, \mathrm{Cr}, \mathrm{Mo})$ were examined. Intermetallic phases are supposed to have a $F e_{x} N i_{y} A l_{1-x-y}$-type chemical formula.

\section{Results and discussion}

Fitting procedure and general results

It is necessary to detail the adopted fitting procedure because many microstructural parameters are deduced for each SANS spectrum (Fig. 1), namely in the case of twophased precipitation. This procedure begins with fitting the SANS spectra associated with the single-phased precipitation kinetics. It has been checked that the shapes of size distributions (Gaussian or log-normal) have no visible impact on the fitting parameters. Mean sizes and volume fractions are well defined and unambiguous for singleprecipitated grades. The standard deviations of the gaussian distributions appear to be systematically around one-third of the mean size. For double-precipitated grades, the early stages of precipitation appear unclear because the size distributions cannot be well separated. Fitting the mean sizes and volume fractions is achieved through the assumption that changes from single to double precipitation are minimal (i.e. in Fig. 2, circles are the nearest possible from squares). However, it must be kept in mind that the global distribution of particles (sizes and volume fractions) is always relevant, but the attribution of a precise volume fraction for one of the population is only carried out with the help of single-precipitation kinetics. When the sizes differ more clearly, the larger precipitates are considered as carbides, because of the comparison with single-precipitation SANS spectra and also taking into account TEM observations in similar steels [19] as well as results from atom probe experiments recently obtained on the steels investigated in this study [20].

Calculating different theoretical values of $A$-ratio for $M_{2} C$ or $F e_{x} N i_{y} A l_{1-x-y}$ compositions additionally with mass conservation of the various chemical elements in the single-precipitation alloys shows that (1) $\mathrm{M}_{2} \mathrm{C}$ are necessarily much richer in chromium than in iron or molybdenum, and there is a tendency for the amount of iron to decrease over the tempering time (substitution with Mo), (2) NiAl particles keep their composition quite far from stoichiometric B2-NiAl, but with a limited amount of iron (particles have a very high magnetic contrast with the ferromagnetic matrix) that tends to decrease, as in the case of carbides. These observations were done on single-precipitated grades, but are supposed to be true for double-precipitated grades too.

Figure 2 shows the sizes and volume fractions of each population of precipitates, for each grade, that were obtained with the described procedure. Uncertainties on the given values could be roughly estimated to $5 \%$ for the sizes, and under $15 \%$ for the volume fractions.

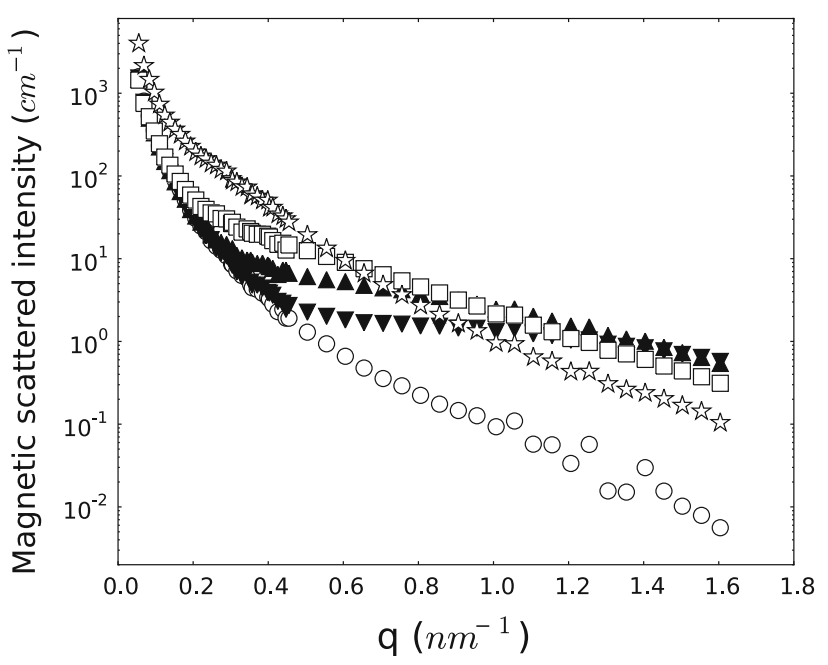

Fig. 1 Magnetic scattering spectrum obtained for various tempering times on the Alloy1014 steel: no tempering (open circles), $1 \mathrm{~h}$ (black down-pointing triangles), $4 \mathrm{~h}$ (filled triangles), $10 \mathrm{~h}$ (open squares), 100 h (asterisks) 
Fig. 2 Comparison between the precipitation kinetics of the different grades: Alloy1014 (filled circles), AlloyM2C (open squares), AlloyNiAl (filled squares), AlloyMix (open circles). a Evolution of the $\mathrm{M}_{2} \mathrm{C}$ sizes according to the tempering time. b Evolution of the $M_{2} C$ volume fraction according to the tempering time. $\mathbf{c}$ Evolution of the intermetallics sizes according to the tempering time. d Evolution of the intermetallics volume fraction according to the tempering time
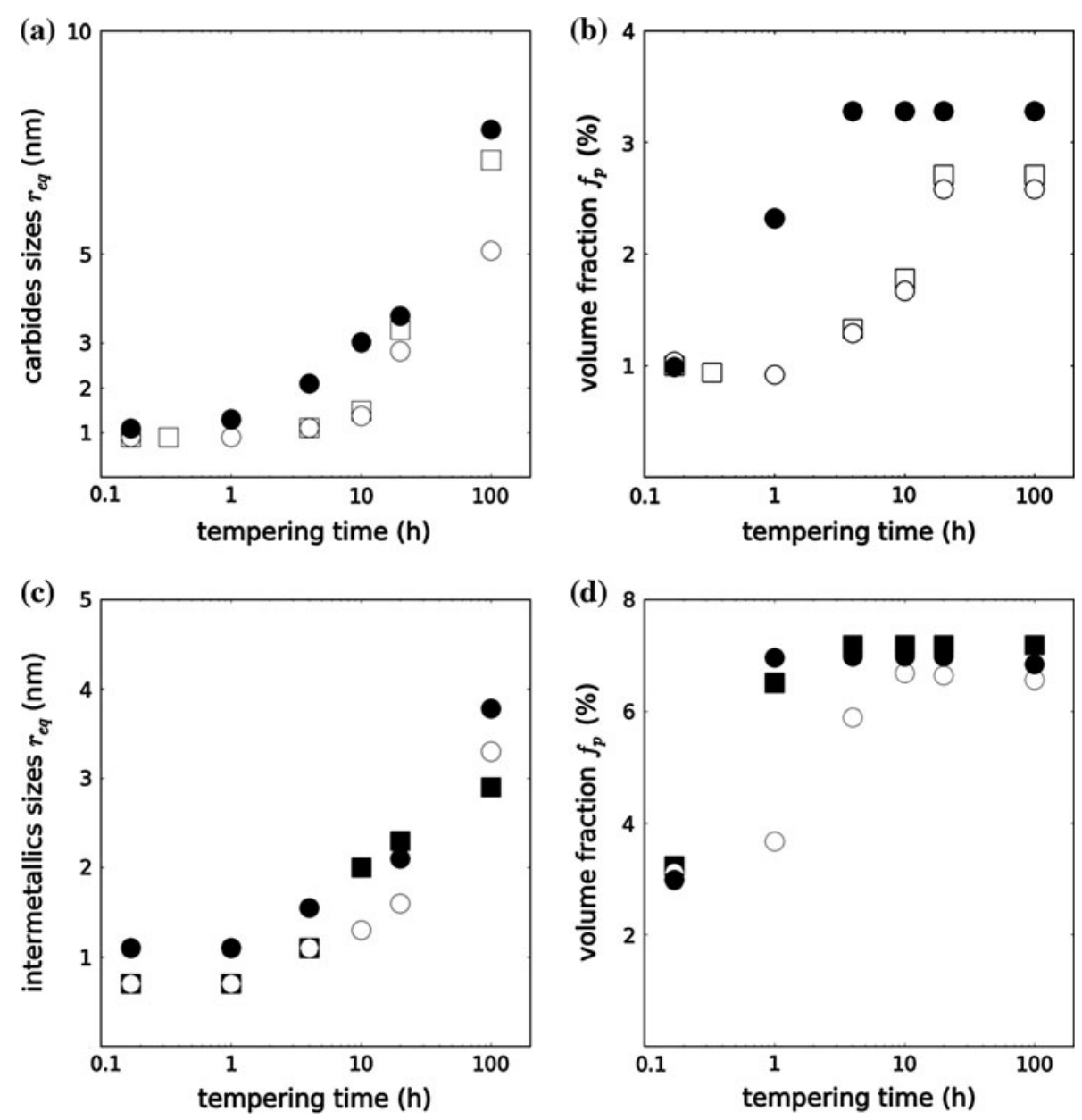

The differences between grades that are discussed below are significantly superior to these uncertainties. Concerning the possible chemical compositions in the double-precipitated grades, the compositions can be deduced only from a correct attribution of the volume fraction for each phase (see above). That is why the uncertainties associated with the particles compositions are difficult to estimate. Hence, composition values for double precipitation have to be considered as qualitative (see Table 2).

Table 2 Chemical composition of precipitates after $100 \mathrm{~h}$ at $500{ }^{\circ} \mathrm{C}$ deduced from SANS experiments (at.\%)

\begin{tabular}{llllllll}
\hline & \multicolumn{3}{l}{$\mathrm{M}$ in $M_{2} C$} & & \multicolumn{3}{l}{ Intermetallics } \\
\cline { 2 - 3 } & $\mathrm{Fe}$ & $\mathrm{Cr}$ & $\mathrm{Mo}$ & & $\mathrm{Fe}$ & $\mathrm{Ni}$ & $\mathrm{Al}$ \\
\hline AlloyM2C & 10 & 70 & 20 & & & \\
AlloyNiAl & & & & & 27 & 38 & 35 \\
AlloyMix & 15 & 65 & 20 & & 20 & 38 & 42 \\
Alloy1014 & 15 & 70 & 15 & & 13 & 36 & 51 \\
\hline
\end{tabular}

Uncertainties are difficult to estimate, the composition values for double precipitation have to be considered as qualitative
Single-phased precipitation kinetics

The AlloyM2C alloy has no aluminium content, so that no intermetallic phase is expected to form during tempering. Precipitation occurs as soon as the tempering begins: after $10 \mathrm{~min}$ at $500{ }^{\circ} \mathrm{C}$, the precipitated volume fraction is nearly $1.0 \%$, and the precipitates size is around $0.9 \mathrm{~nm}$. Initial composition of the metal $\mathrm{M}$ in the $\mathrm{M}_{2} \mathrm{C}$ carbides has been evaluated around $70 \% \mathrm{Cr}-30 \% \mathrm{Fe}$. The growth stage of precipitation is quite long, as coalescence is taking place after $20 \mathrm{~h}$ of tempering. At this time, the carbides have grown to a size $\left(r_{\mathrm{eq}}\right)$ of $3.3 \mathrm{~nm}$, and the precipitated volume fraction is $2.7 \%$. Moreover, the carbides shapes evolved from spheres to ellipsoids (ell =2.3). After $100 \mathrm{~h}$ at $500{ }^{\circ} \mathrm{C}$ (final state), $r_{\mathrm{eq}}$ is measured at $7.1 \mathrm{~nm}(\mathrm{ell}=4)$ for a volume fraction still remaining at $2.7 \%$. Final composition of $\mathrm{M}$ is near $70 \% \mathrm{Cr}-10 \% \mathrm{Fe}-20 \% \mathrm{Mo}$. Fe content has nearly monotonically decreased during precipitation, while Mo content has increased.

The AlloyNiAl alloy has no carbon content, so no precipitation of carbides was observed. Intermetallics number density is 10 times higher than carbides number density: after $10 \mathrm{~min}$ at $500{ }^{\circ} \mathrm{C}$, the precipitated volume fraction is already 
$3.2 \%$, and after $1 \mathrm{~h} 6.5 \%$, while the precipitates size is around $0.7 \mathrm{~nm}$. This high number density, $1.1 \times 10^{19}$ and $2.4 \times$ $10^{19} \mathrm{~cm}^{-3}$, respectively, is probably due to a high nucleation flux. Initial composition of the intermetallic phase has been evaluated around $37 \% \mathrm{Fe}-35 \% \mathrm{Ni}-28 \% \mathrm{Al}$. The growth stage of precipitation is quite short, leading after only $4 \mathrm{~h}$ at $500{ }^{\circ} \mathrm{C}$ to a slow coalescence. After $100 \mathrm{~h}$ of precipitation (final state), $r_{\mathrm{eq}}$ is equal to $2.9 \mathrm{~nm}$ and the precipitated volume is $7.2 \%$. The estimated final chemical composition is around $27 \% \mathrm{Fe}-38 \% \mathrm{Ni}-35 \% \mathrm{Al}$.

\section{Two-phased precipitation kinetics}

Figure 2 compares monoprecipitation and multiprecipitation grades through the sizes and volume fractions of precipitates. The chemical composition of the AlloyMix grade is very similar to AlloyM2C and AlloyNiAl in composition (see Table 1), except that the carbon and aluminium contents allow the precipitation of both carbides and intermetallic phases. An unchanged carbides precipitation is compatible with the obtained results. The presence of intermetallic precipitates does not induce any change in the fitting parameters concerning the carbides (shapes, sizes and number density) in order to fit experimental data. But the intermetallic precipitation is different from the AlloyNiAl one. The $\mathrm{NiAl}$ growth regime is slower and longer than without $M_{2} C$ carbides. Indeed, precipitated volume increases more slowly: after $1 \mathrm{~h}$ of thermal treatment, it reaches $3.7 \%$ instead of $6.5 \%$, and after $20 \mathrm{~h}$ of thermal treatment, precipitates mean size is $1.3 \mathrm{~nm}$ instead of $2 \mathrm{~nm}$. These differences are significant at long tempering times where both populations of particles can be well separated from each other. This could be due to the influence of $M_{2} C$ carbides on the precipitation of intermetallic phases or to the influence of the carbon content on the matrix diffusive properties. The vacancies migration energy in steels is known to be very sensitive to the carbon content, but for extremely low carbon contents only, around 10 ppm: even in AlloyNiAl, this energy must be stabilized to its high-content value due to impurities [21]. A final intermetallic composition of $20 \% \mathrm{Fe}-38 \% \mathrm{Ni}-42 \% \mathrm{Al}$, similar to the monoprecipitation case, is compatible with the obtained experimental data.

The Alloy1014 grade (composition given in Table 1) presents small difference from the AlloyMix grade, but the precipitation kinetics of carbides are obviously modified. First, carbides precipitation is faster: the growth stage is shorter but faster, and coalescence starts after only $4 \mathrm{~h}$ at $500{ }^{\circ} \mathrm{C}$. At this time, the carbides have already grown to a size of $2.1 \mathrm{~nm}$ (to be compared with $1.1 \mathrm{~nm}$ in AlloyM2C), and the precipitated volume fraction is $3.2 \%$ (only $1.3 \%$ in
AlloyM2C). The maximum number density of carbides about $1.8 e 24 \mathrm{~m}^{-3}$ is quite similar in all the carbides containing alloys but this maximum is reached for a size of particles higher in the Alloy1014 than in AlloyM2C and AlloyMix. The Co content clearly enhances the $M_{2} C$ precipitation.

In other respects, intermetallic phases are less influenced by the $M_{2} C$ precipitation: the same amount of volume fraction is obtained in the early stages $(3.0 \%$ in $10 \mathrm{~min}$ instead of $3.2,7.0 \%$ in $1 \mathrm{~h}$ instead of $6.5 \%$ ), and the sizes evolution over the tempering time is also very similar. Final composition is $13 \% \mathrm{Fe}-36 \% \mathrm{Ni}-51 \% \mathrm{Al}$, with a low iron chemical content compared with the case of monoprecipitation (this is the only remarkable difference).

In conclusion, there are significant differences between the precipitation kinetics depending on carbon, aluminium and cobalt contents. The corresponding processes remain unclear because it is not possible to be assertive concerning nucleation in the two-phased precipitation kinetics. As long as both mean sizes are of the order of $1 \mathrm{~nm}$, populations cannot be separated. Consequently, the nucleation sequence is not deduced, even though growth and coalescence regimes could have been derived. The small mean radius and very large number density of intermetallic particles suggest a homogeneous nucleation mechanism, whereas $M_{2} C$ carbides could undergo heterogeneous nucleation. The presence or absence of intermetallic particles must have a large influence on heterogeneous nucleation of carbides. This last point appears to be possible, the more in Alloy1014, the less in AlloyMix.

\section{Precipitation hardening}

The best material would combine a high tensile strength with sufficient ductility. The variation of the tensile yield strength $\sigma_{0.2}(0.2 \%$ proof stress $)$ with the tempering time could be related to the quantitative analysis of the nanoscaled precipitations.

Figure 3 shows the variation of the tensile yield strength for the studied grades. Between 4 and $20 \mathrm{~h}$ of tempering, the strengths are approximately constant, and it could be noticed that the precipitate-free AlloyStd grade has a lower tensile strength than any other one, both single-precipitated grades have similar strengths (300 MPa above the AlloyStd grade) and, finally, both double-precipitated grades are much stronger than the others, with a very high strength for the Alloy1014 grade, around 2,000 $\mathrm{MPa}$ (the ultimate tensile strength reaches 2,200 $\mathrm{MPa}$ ).

Comparing experimental structural hardening with theoretical values requests at first that the matrix mechanical strength including solid solution, grain and lath boundary effects as well as friction stress and dislocation strengthening contributions, has been previously estimated. Hence, 


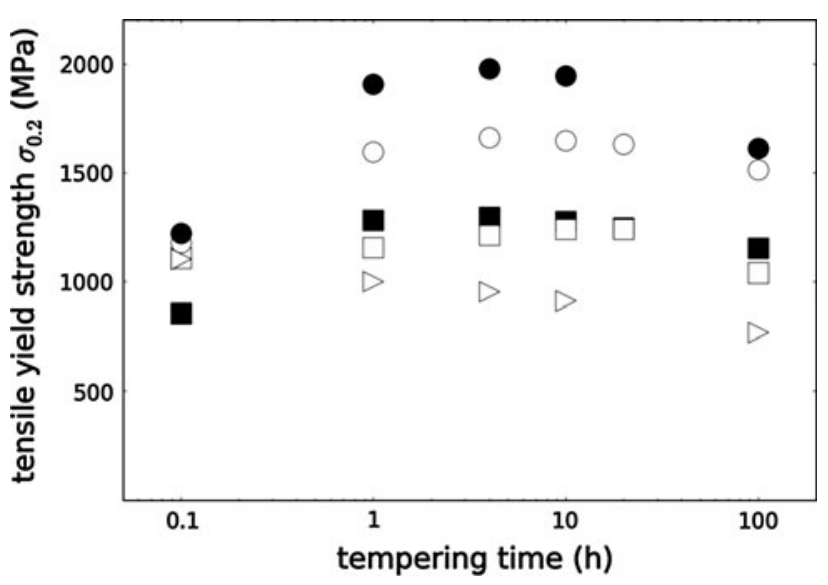

Fig. 3 Results of the mechanical tests: tensile yield strengths of the different grades according to the tempering time. AlloyStd tensile strength is also figured here (white right-pointing triangles). The $x$ axis is logarithmic for readability reasons, forcing the visualisation of $t=0$ measurements at an arbitrary $t_{0}>0$ value, equal to $0.1 \mathrm{~h}$

the tensile strength of a precipitate-free alloy with same thermal treatment has been subtracted. However, effective differences in the strengths already appear before the tempering treatment, consequently before precipitation, because the matrix are probably different (see Fig. 3). It is assumed that these strength differences (for example, solid solution hardening) are constant over the tempering time, and the corresponding value is systematically subtracted.

The models used to describe the particles-precipitates interactions are chosen through the study of both monoprecipitation grades AlloyM2C and AlloyNiAl.

$\beta$-NiAl precipitates were observed as cubic-ordered precipitates with low lattice mismatch and coherent with the martensitic matrix [19]. It is expected an atomic-order strengthening, corresponding to the creation of disorder in the form of antiphase domain boundaries (APB) of surface energy $\gamma_{\text {APB }}$ on the slip plane within the precipitates [22]. The evaluation of hardening in the AlloyNiAl grade gives very relevant information: the structural hardening is relatively high and constant, while the precipitated volume fraction is quickly stabilized at its equilibrium value and while the particles go on growing. Therefore, the hardening does probably depend very weakly on the size of the particles but only on the volume fraction, indicating a medium-pair coupling between dislocations and intermetallic particles (so called peak-aged particles, see [22, 23]). Medium-pair coupling is a transition between weak-pair coupling where particles are sheared by single dislocations, and strong-pair coupling where two dislocations lie inside the sheared particle at the same time. This distinction has been extensively studied in the case of Ni-based superalloys by Hüther and Reppich [24].

If the intermetallic particles were bigger (over-aged particles), a transition to a strong-pair coupling mechanism is expected, with a resulting lower strengthening, this last becoming conversely proportional to the size of the $\mathrm{NiAl}$ particles. A rough estimation of the hardening in this last regime is the half of the Orowan hardening. This is not the case here in AlloyNiAl grade (hardening is constant), where the particles sizes are smaller than $3 \mathrm{~nm}$. The theory of Labusch and Schwarz [22, 25], applying to finely dispersed and high number density particles, is chosen in order to perform a slight correction of the classical model of Friedel, which applies only to particles in low number density. The strengthening for peak-aged particles is then given by the following equation:

$\tau_{\mathrm{NiAl}}=\frac{\gamma_{\mathrm{APB}}}{2 b}\left[\left(\frac{3 \pi}{8 f_{p}}\right)^{1 / 2}-f_{p}\right] \times\left[1+C_{\mathrm{SL}} f_{p}^{1 / 2} / 2\right]$

where $\tau$ is the critically resolved shear stress, $b$ is the Burgers vector modulus, $C_{\mathrm{SL}}$ is an empirical constant close to unity.

This equation is fitted to experimental data through correct choices of the parameters: $b$ is equal to $0.248 \mathrm{~nm}$ in martensitic iron, $\mu$ (matrix shear modulus) is equal to $80 \mathrm{GPa} . C_{\mathrm{SL}}$ has been fixed to 1 . The only fitting parameter is $\gamma_{\mathrm{APB}}$ equal to $405 \mathrm{~mJ} \mathrm{~m}^{-2}$. The reported value for $\gamma_{\mathrm{APB}}$ in B2-NiAl crystals in literature is $0.8 \mathrm{~J} \mathrm{~m}^{-2}$, but Hong and Freeman [26] showed that this value can decrease rapidly if the stoichiometry of the phase changes, as in the case of $\mathrm{Ni}_{6} \mathrm{Al}_{4} \mathrm{Cr}_{2}$ and $\mathrm{Ni}_{4} \mathrm{Al}_{6} \mathrm{Cr}_{2}$, where the surface energy of antiphase boundaries become 0.25 and $0.51 \mathrm{~J} \mathrm{~m}^{-2}$ respectively. Here, SANS measurements tend to show a substitution of $\mathrm{Ni}$ atoms by $\mathrm{Fe}$ atoms in the intermetallic particles (see Table 2), so that the fitted value of $\gamma_{\mathrm{APB}}$ seems satisfactory.

The observed $M_{2} C$-matrix interfaces are not fully coherent. This suggests that the same strengthening mechanism is not likely to occur, in addition to the differences in sizes and number densities. The strength of these particles is evaluated thanks to the experimental data of AlloyM2C yield stress, assuming the classical model of Friedel [27]:

$\tau_{C}=\frac{2}{b L T^{1 / 2}}\left(\frac{F}{2}\right)^{3 / 2}$

where $F$ is the strength of the particle as an obstacle, $L$ the average distance between precipitates in the glide plane and $T$ the dislocation line tension. Using $T=\mu b^{2} / 2$ and $L=r \sqrt{2 \pi / f}$ in this last equation, one can evaluate the critical angle $\phi_{C}$ or the normalised particles strength $k$ following the same approach as Deschamps et al. [28]:

$k=\frac{\langle F\rangle}{2 T}=\cos \frac{\phi_{C}}{2}=\left(\sqrt{\frac{2 \pi}{3}} \frac{r}{M \mu b} \frac{\Delta \sigma_{0.2}}{f_{p}^{1 / 2}}\right)^{2 / 3}$

where $M=3$ is the Taylor constant, and assuming spherical precipitates of radii $r=r_{\text {eq }}$. The deduced 
values of $k$ in AlloyM2C grade $(<0.5)$ and the deduced values of $\phi_{C}\left(>125^{\circ} \mathrm{C}\right)$ indicate that the $M_{2} C$ carbides strengthening mechanism differs from Orowan description $(k=1)$. The evolution of $k$ (or $\langle F\rangle$ ) with the mean radius of the particles is compatible with a precipitation hardening that is caused by a difference in shear modulus between particle and matrix. Nembach [29] proposed a general power-law expression based on the approximation of Friedel and on numerical simulations:

$k \propto\langle F\rangle \propto \alpha_{1}\left(\frac{r}{b}\right)^{\beta_{1}}$

leading to the following critically resolved shear stress:

$\tau_{C_{F}}=C_{F} \frac{\left(\Delta \mu b^{2}\right)^{3 / 2} \alpha_{1}^{3 / 2} r^{\left(3 \beta_{1} / 2-1\right)} f_{p}^{1 / 2}}{b^{\left(3 \beta_{1} / 2+1\right.}(2 \pi S)^{1 / 2}}$

where $C_{F}$ is a constant close to $1.4, S$ is the tension line of the dislocation, $\alpha_{1}$ and $\beta_{1}$ are fitted by numerical simulations to values in the range 0.096-0.162 and 0.688-0.905, respectively. These results concerning $\alpha_{1}$ and $\beta_{1}$ were valid in the range of radii $8 b \geq r \geq 50 b$, corresponding for $b=0.248$ to $2.0 \mathrm{~nm} \geq r \geq 12.4 \mathrm{~nm}$. It should be noted that the low number density of carbides does not require any correction of the Friedel approximation.

First, it is needed to have an input value for $M_{2} C$ shear modulus. As it cannot be found in bibliography, it has been approximated through global correlations between lattice parameters, melting point and Young modulus [30]. The evaluation resulted in a modulus of $108 \mathrm{GPa}$ (see Appendix 2). $C_{F}$ is taken equal to $1.4, S$ equal to $\mu_{\text {matrix }} b^{2} / 2 . \alpha_{1}$ and $\beta_{1}$ are fitted through the AlloyM2C hardening data, giving respective values of 0.084 and 0.55 . These last values are found to be slightly weaker than expected but satisfactory. It should be noted that 0.55 being near $2 / 3$, the hardening decreases very slowly when $r$ increases (evolution of power -0.18 ), so that $M_{2} C$ hardening is not very sensitive to the mean radius in the explored ranges of sizes, as noticed for NiAl particles. The obtained values of $\alpha_{1}$ and $\beta_{1}$ lead to a transition towards Orowan process (i.e. $k=1$ ) when the mean radius of particles reaches $30 \mathrm{~nm}$, which seems a relevant value.

The application of the models above on the hardening of AlloyM2C and AlloyNiAl grades during tempering has been used to deduce the correct parameters to enter for multiphase precipitation hardening. For combined precipitation, the contributions of both populations have to be considered together. Hardening contributions are summed in this way $[31,32]$ :

$\Delta \sigma_{0.2}^{2}=M^{2}\left(\tau_{\mathrm{NiAl}}^{2}+\tau_{C_{F}}^{2}\right)$

In Fig. 4b, the values given by the previous equation were compared with the measured mechanical properties of (a)

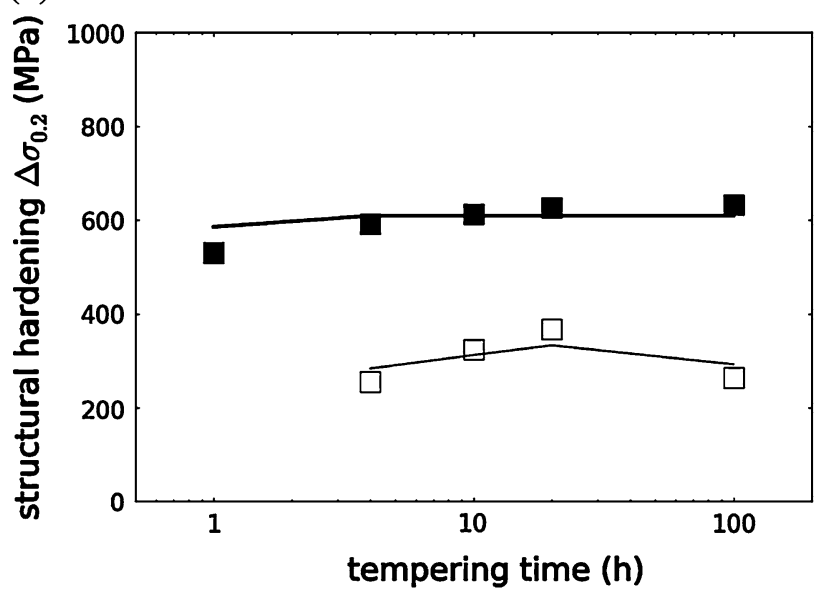

(b)

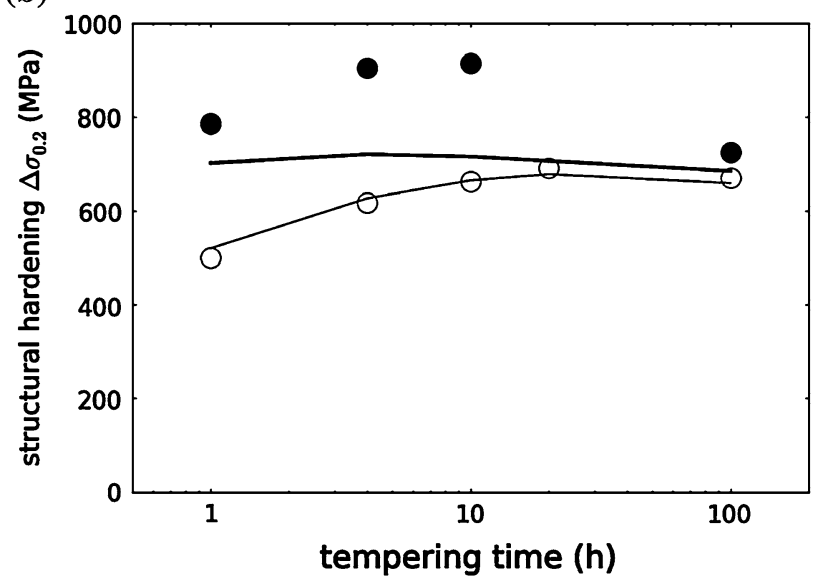

Fig. 4 Variations of $\Delta \sigma$ with the tempering time: a monoprecipitation alloys, b joint precipitation alloys; direct measurements (symbols) compared with evaluations by Eqs. 10, 14 and 15 through SANS experiments (lines). a AlloyM2C (open squares) and AlloyNiAl (filled squares) monoprecipitation alloys. b AlloyMix (open circles) and Alloy1014 (filled circles) joint precipitation alloys

AlloyMix and Alloy1014 grades. The Alloy1014 hardening is underestimated, but the evolution of AlloyMix hardening is fairly well reproduced. Changing the exponent used in Eq. 15 from 2 to 1.5 resulted in an opposite situation where AlloyMix hardening would be overestimated and Alloy1014 well reproduced, which does not solve the question. The single precipitation hardenings were calibrated on cobalt-free grades, so that it is natural to observe a better estimation on AlloyMix hardening. However, the reason why Alloy1014 has a stronger hardening than that calculated remains unclear. The resulting tensile strength is impressive (U.T.S. of 2,200 MPa) and is not completely understood by this study.

Considering now the differences between AlloyNiAl and AlloyMix grade, it must be noticed that the structural hardening of both grades are in the same order of magnitude. But there is an effective enhancement of the mechanical 
properties by adding carbon to AlloyNiAl (and consequently carbides) in terms of ductility, because AlloyNiAl grade is too brittle for any industrial application. In top of that, AlloyMix has a better tensile strength at the beginning of the tempering, so that the absolute $\sigma$ is far higher than AlloyNiAl grade. The main conclusion is that the advantageous consequences of combined precipitation on mechanical properties are numerous.

\section{Conclusion}

The Alloy1014 martensitic industrial steel grade and three similar experimental AlloyM2C (without $\mathrm{Co}$ and $\mathrm{Al}$ ), AlloyNiAl (without Co and C) and AlloyMix (without Co) grades were studied by SANS experiments and mechanical tests, with thermal tempering of different durations, in order to follow single (AlloyM2C and AlloyNiAl) or double (AlloyMix and Alloy 1014) precipitation as well as its impact on the mechanical properties of the investigated materials. The main conclusions can be summarised as follows.

Intermetallic precipitation consists in a very fine dispersion of spherical particles, as in a homogeneous nucleation process, and the coalescence process is very slow. $M_{2} C$ carbides grow more quickly and their number density is always very small compared with that of the intermetallic particles. Precipitation kinetics are strongly dependent on the presence of carbon, aluminium and cobalt for each precipitating phase. The mutual influences of both populations of precipitates remain unclear, since nucleation sequence cannot be decided. However, there was no obvious difference in the carbides growth kinetics due to the presence of intermetallic particles. Intermetallic growth kinetics is slowed down in presence of carbides. The cobalt impact on precipitation is strong: it accelerates the $\mathrm{M}_{2} \mathrm{C}$ precipitation, while keeping an intermetallic precipitation as quick as in single precipitation.

The mechanical properties of these grades were tested: the double-precipitated grades exhibit higher tensile strengths than the others, and the Alloy1014 grade has a much higher tensile strength than AlloyMix grade, even though the only difference is the presence of cobalt in the chemical composition. These experimental results were used to relate structural hardening to the particles sizes and the precipitated volume fractions. The structural hardening results from both populations of precipitates: order hardening due to the creation of antiphase boundaries by dislocations when they shear the intermetallic particles, and shear modulus contrast hardening in the case of $M_{2} C$ carbides.
Additional observations in transmission electron microscopy could give more information on strengthening mechanisms. Thermodynamic modelling will be necessary to explain the mutual influences of both populations of precipitates on the microstructure growth, and also the role of cobalt.

\section{Appendix 1}

The form factor of a gaussian distribution of ellipsoids defined by $r_{i}, \sigma_{i}$ and ell ${ }_{i}$ (see "SANS experiments" section) has the following expression:

$\left|F_{\text {gauss }}(q)\right|^{2}=\frac{\int_{0}^{2 r_{i}} \frac{4 \pi}{3} \operatorname{ell}_{i} r^{6} e^{-\left(r-r_{i}\right)^{2} /\left(2 \sigma_{i}^{2}\right)}\left|F_{\mathrm{ell}}(q)\right|^{2} d r}{\int_{0}^{2 r_{i}} r^{3} e^{-\left(r-r_{i}\right)^{2} /\left(2 \sigma_{i}^{2}\right)} d r}$

where $F_{\text {ell }}$ is given by

$\left|F_{\mathrm{ell}}(q)\right|^{2}=\int_{0}^{1}\left|F_{\mathrm{sph}}(q)\right|^{2}\left(q r_{i} \sqrt{1+x^{2}\left(\mathrm{ell}_{i}^{2}-1\right)}\right) d x$

The form factor of a sphere of radius $r_{i}$ is recalled:

$\left.\left|F_{\mathrm{sph}}(q)\right|^{2}=9 \frac{\sin q r_{i}-q r_{i} \cos q r_{i}}{\left(q r_{i}\right)^{3}}\right)^{2}$

\section{Appendix 2}

The shear modulus is considered as proportional to $T_{\mathrm{m}} a^{-3}$ where $T_{\mathrm{m}}$ is the melting point and $a$ the cubic root of the volume per atom. For the sake of simplicity, it has been considered that $\mathrm{M}_{2} \mathrm{C}$ shear modulus was a linear combination of $\mathrm{Cr}_{2} \mathrm{C}(75 \%)$ and $\mathrm{Mo}_{2} \mathrm{C}(25 \%)$. Iron is used as a reference. The calculation of shear modulus of $\mathrm{Cr}_{2} \mathrm{C}$ and $\mathrm{Mo}_{2} \mathrm{C}$ with the parameters given in the Table 3 leads to a $\mathrm{M}_{2} \mathrm{C}$ shear modulus of $108 \mathrm{GPa}$. Melting points were found in [33].

Table 3 Estimation of the shear modulus of $M_{2} C$ carbides (bold) from their melting temperature and cubic root of the volume per atom

\begin{tabular}{llll}
\hline & $\mathrm{Fe}$ & $\mathrm{Cr}_{2} \mathrm{C}$ & $\mathrm{Mo}_{2} \mathrm{C}$ \\
\hline$T_{m}\left({ }^{\circ} \mathrm{C}\right)$ & 1538 & 1800 & 2500 \\
$a(\mathrm{~nm})$ & 0.228 & 0.218 & 0.231 \\
$G(\mathrm{GPa})$ & 80 & $\mathbf{1 0 5}$ & $\mathbf{1 1 8}$ \\
\hline
\end{tabular}




\section{References}

1. Senuma T (2001) ISIJ Int 41:520

2. Garrison WM Jr, Rhoads MA (1996) Trans Indian Inst Met 49:151

3. Jeniski RA, Bayha TD (2004) 15th Advanced aerospace materials and processes conference and exposition, Seattle, 7-10 June 2004

4. Carinci GM, Olson GB, Liddle JA, Chang L, Smith GDW (1990) In: Olson GB, Azrin M, Wright ES (eds) Proceedings of the 34th Sagamore Army materials conference titled innovations in ultrahigh strength steel technology, Lake George, New York, p 179

5. Ayer R, Machmeier PM (1993) Metall Trans 24:1943

6. Novotny PM (2007) US Patent Application Publication $0,113,931 \mathrm{~A} 1$

7. Xie X, Zeng Y, Wang M, Fan H (2011) In: Weng Y, Dong H, Gan Y (eds) Advanced steels. Springer, Berlin, p 93

8. Cotton JP (1991) In: Lindner P, Zembs Th (eds) Neutron, X-ray and light scattering. Elsevier, Amsterdam, p 19

9. Villars P, Calvert LD (1985) Pearson's handbook of crystallographic data for intermetallic phases. American Society for Metals, Materials Park

10. Sears VF (1992) Neutron News 3:26

11. Kazjar F, Parette G (1980) Phys Rev B 22:5471

12. Sanyal B, Bose SK (2000) Phys Rev B 62:12730

13. Bardos DI, Beeby JL, Aldred AT (1979) Phys Rev 177:878

14. Aldred AT (1976) Phys Rev B 14:219

15. Wertheim MS (1963) Phys Rev Lett 10:321
16. Thiele EJ (1963) J Chem Phys 39:474

17. Mathon MH, de Novion CH (1999) J Phys IV Fr 9:127

18. Ashcroft NW, Lekner J (1966) Phys Rev 145:83

19. Erlach SD, Leitner H, Bischof M, Clemens H, Danoix F, Lemarchand D, Siller I (2006) Mater Sci Eng A 429:96

20. Danoix F, Danoix R, Akre J, Grellier A, Delagnes D (2011) J Microsc. doi:10.1111/j.1365-2818.2011.03537x

21. Mathon MH, Barbu A, Dunstetter F, Maury F, Lorenzelli N, de Novion CH (1997) J Nucl Mater 245:224

22. Reppich B (1993) In: Cahn RW, Haasen P, Kramer EJ, Mughrabi $\mathrm{H}$ (eds) Materials science and technology, vol 6, plastic deformation and fracture of materials. Wiley-VCH, Weinheim, p 311

23. Mohles V, Nembach E (2001) Acta Mater 49:2405

24. Hüther W, Reppich B (1978) Z Metallkunde 69:628

25. Labusch R, Schwarz RB (1978) J Appl Phys 49:5174

26. Hong T, Freeman AJ (1991) Phys Rev B 43:6446

27. Foreman AJE, Makin MJ (1967) Can J Phys 45:511

28. Deschamps A, Militzer M, Poole WJ (2001) ISIJ International 41(2):196

29. Nembach E (1983) Phys Status Solidi A 78:571

30. Grimvall G, Sjödin S (1974) Phys Scr 10:340

31. Ardell AJ (1985) Metall Trans A 16:2131

32. Kocks UF, Argon AS, Ashby MF (1975) Prog Mater Sci 19:303

33. Massalski (1990) Binary alloys phase diagrams. ASM International, Materials Park

34. Erlach S, Siller I, Leitner H, Clemens H (2008) Int J Microstruct Mater Prop 3:373 